\title{
BARIATRIC SURGERY AND OSTEOPOROSIS
}

\author{
Mara Carsote ${ }^{1}$, Razvan Petrescu ${ }^{2}$, Adriana Elena Nica ${ }^{3}$, Adina Ghemigian ${ }^{1}$, \\ Dan Nicolae Paduraru ${ }^{3}$, Ana Valea ${ }^{4}$ \\ I "C.I. Parhon" National Institute of Endocrinology, \\ "Carol Davila" University of Medicine and Pharmacy, Bucharest \\ 2 "Medlife", Brasov \\ ${ }^{3}$ University Emergency Hospital, "Carol Davila” University of Medicine and Pharmacy, Bucharest \\ ${ }^{4}$ Clinical County Hospital, "Iuliu Hatieganu” University of Medicine and Pharmacy, Cluj-Napoca
}

\begin{abstract}
Introduction. Bariatric surgery, regardless the type of approach, has aggressively extended nowadays. The procedure saves lives due to substantial improvement of severe cardio-metabolic co-morbidities, but the influence of nutritional status might not be completely harmless including bone and muscle changes. Our purpose is to introduce data regarding skeleton after bariatric surgery. This is a narrative mini-review including papers from PubMed. A selection of 33 papers has been done.

General data. Longitudinal better than cross-sectional studies confirmed an annual rate of losing bone mineral density at lumbar and femoral neck of $3-10 \%$ starting with first year after surgery and continuing within the third year; low vitamin $\mathrm{D}$ and calcium absorption with associated secondary hyperparathyroidism is described; others anomalies include elevated bone remodelling markers, damage of bone microarchitecture, fracture healing disturbances and sarcopenia.

Conclusion. Overall, despite spectacular results after bariatric surgery, the bone and muscle are expected to suffer a level of deterioration, which should be taken into account for assuring an adequate quality of life and an immediate and distant good post-operatory prognosis.
\end{abstract}

Keywords: bariatric surgery, osteoporosis, bone

\section{INTRODUCTION}

Bariatric surgery, regardless the type of procedure, has aggressively extended nowadays not only to adults, but also to extreme ages (1-3). The procedure saves lives due to substantial improvement of severe co-morbidities as type 2 diabetes mellitus, obesity, high blood pressure, elevated uric acid and lipid profile disturbances, chronic inflammation, osteoarthritis, including the fact that it lowers the risk of some cancers and resets overall survival (46). Recent data, though, reflected that influence of nutritional status might not be completely harmless (like anaemia, vitamins and nutrients as copper, zinc, selenium that may be lost, hypoalbuminemia etc.) thus a connection with bone health in a negative way has been established (7-9). Moreover, some anaesthesia difficulties are presented from the begging during surgery and post-operatory (10).

\section{OBJECTIVE}

Our purpose is to introduce data regarding skeleton observations after bariatric surgery.

\section{MATERIAL AND METHOD}

This is a narrative mini-review including papers from PubMed. The area was restricted to English published manuscripts and humans. A selection of 33 papers has been done.

\section{GENERAL DATA}

The multidisciplinary team that will take care of a bariatric surgery patient also has to consider the metabolic and nutritional implications to skeleton 
(11-13). A rapid weight loss will aggravate the protein waste, including skeletal muscle damage accelerating sarcopenia, thus the need for progressive physical exercise to improve the general status of health (11). The two well known approaches, Rouxen-Y gastric bypass as well as sleeve gastrectomy cause lack of vitamin D, which is necessary to be replaced together with calcium supplements (1113). The exact doses differs with approach, despite the general recognition of D-replacement (14). Also, the target to treat when it comes to optimal levels of 25-hydroxyvitamin D in prior obese population is still controversial (15). A certain level of malabsortion is expected anyway and this might be the weak point in successful recovery after bariatric surgery without significant side effects $(12,13)$. Endocrine anomalies that follows weight, inflammation, metabolic and nutritional changes involve fat - produced adipokines as leptin, adiponection, sexual hormones as estrogens and testosterone, inflammatory cytokines acting as autocrine agents and gut- derivate endocrine products as ghrelin, GLP-1 (glucagon- like peptide 1), GIP (gastric inhibitory peptide), 5-hydroxytryptamine etc $(12,13,16)$. The bone deterioration correlated with severe weight loss after bariatric surgery includes micro-architecture disturbances, negative influence on fall, Bone Mineral Density (BMD) at central Dual-Energy XRay Absorptiometry (DXA) decrease, elevated bone turnover markers, hypovitaminosis D - related secondary hyperparathyroidism (17-19). One study on women after gastric by-pass revealed they had a significant loss of BMD at the lumbar spine and femoral neck and total body after 6 , respective 12 months, while after sleeve gastrectomy the decrease was only for total body (20). BMD loss was correlated with ghrelin levels (20). Also, it seems that damage of DXA - BMD is higher if BMD is higher at baseline (20). Proposed mechanisms for skeleton anomalies after Roux-en-Y gastric bypass also includes intestinal loss of calcium and vitamin $\mathrm{D}$, impairment of mechanical load etc (21). Artefacts of interpreting DXA and quantitative computer tomography are described related to adipose tissue amount changes (22). Other studies found no difference between the two procedures one year after (23-25). The rate of BMD decline seems more important that punctual value at some moment, that is why the diagnosis itself of osteoporosis is actually rare in most studies (23-25). All the mentioned disturbances are more intense in menopausal woman (23-25). The importance of longitudinal studies opposite to cross-sectional is revealed by annual rate of skeleton anomalies after surgery, for instance, a decline of $10 \%$ for femoral neck areal BMD and $8 \%$ for spine BMD has been found within 12 months after bariatric procedure was done (26). A pre-existing nutritional or bone damage represents supplementary risk factors for skeleton deterioration post-operatory (27). Other observations referring to a population with a mean age of 46 years showed a femoral neck DXA- BMD loss of $10.2 \%$, respective $3.2 \%$ at lumbar region after 12 months from surgery, while later on, during the third year after gastric procedure the decrease was plus $2.7 \%$, respective $3.1 \%$ (28). Apart from menopausal status, the more advanced age is an additional risk factor for osteoporosis, but remarkably,

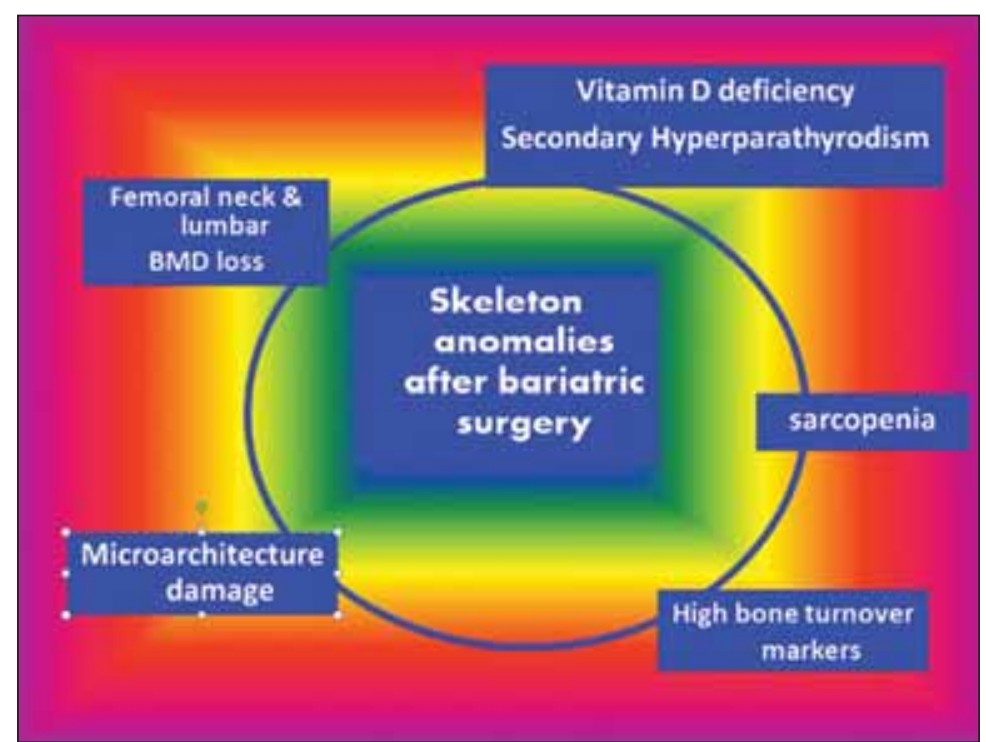

FIGURE 1. Bone and muscle anomalies after bariatric

surgery

$\mathrm{BMD}=$ Bone Mineral Density at central DXA 
the diagnosis itself of newly discovered osteoporosis is rare in comparison to similar population without prior bariatric surgery (28-30). On the contrary, higher levels of remodeling markers and parathyroid hormone are expected, as well as a diminution of muscle mass (myopenia), while the changes in nutritional status may impair the recovery and healing process after a potential fragility fracture (3133).

\section{REFERENCES}

1. Coles N., Birken C., Hamilton J. Emerging treatments for severe obesity in children and adolescents. BMJ. 2016 Sep 29; 354:i4116. doi: 10.1136/bmj.i4116.

2. Fouse T., Schauer P. The Socioeconomic Impact of Morbid Obesity and Factors Affecting Access to Obesity Surgery. Surg Clin North Am. 2016 Aug; 96(4):669-79.

3. Ahmad N.N., Butsch W.S., Aidarous S. Clinical Management of Obesity in Women: Addressing a Lifecycle of Risk. Obstet Gynecol Clin North Am. 2016 Jun; 43(2):201-30.

4. Osland E., Yunus R.M., Khan S., et al. Diabetes improvement and resolution following laparoscopic vertical sleeve gastrectomy (LVSG) versus laparoscopic Roux-en-Y gastric bypass (LRYGB) procedures: a systematic review of randomized controlled trials. Surg Endosc. 2016 Sep 13. [Epub ahead of print]

5. Shah A.S., D’Alessio D., Ford-Adams M.E., et al. Bariatric Surgery: A Potential Treatment for Type 2 Diabetes in Youth. Diabetes Care. 2016 Jun; 39(6):934-40.

6. Zhou X., Yu J., Li L., et al. Effects of Bariatric Surgery on Mortality, Cardiovascular Events, and Cancer Outcomes in Obese Patients: Systematic Review and Meta-analysis. Obes Surg. 2016 Mar 18. [Epub ahead of print]

7. Stein J., Connor S., Virgin G., et al. Anemia and iron deficiency in gastrointestinal and liver conditions. World J Gastroenterol. 2016 Sep 21; 22(35):7908-25.

8. Van Gossum A., Pironi L., Chambrier C., et al. Home parenteral nutrition (HPN) in patients with post-bariatric surgery complications. Clin Nutr. 2016 Sep 8. pii: S02615614(16)30235-7. doi: 10.1016/j.clnu.2016.08.025. [Epub ahead of print]

9. Garg T., Birge K., Ulysses Rosas, et al. A postoperative nutritional consult improves bariatric surgery outcomes. Surg Obes Relat Dis. 2016 Jun;12(5):1052-6. doi: 10.1016/j.soard.2016.01.008. Epub 2016 Feb 12

10. Pompilio C.E., Pelosi P., Castro M.G. The Bariatric Patient in the Intensive Care Unit: Pitfalls and Management. Curr Atheroscler Rep. 2016 Sep; 18(9):55. doi: 10.1007/s11883-016-0606-1.

11. Thibault R., Pichard C. Overview on nutritional issues in bariatric surgery. Curr Opin Clin Nutr Metab Care. 2016 Aug 31. [Epub ahead of print]

12. Pizzorno L. Bariatric Surgery: Bad to the Bone, Part 1. Integr Med (Encinitas). 2016 Mar; 15(1):48-54.

13. Pizzorno L. Bariatric Surgery: Bad to the Bone, Part 2. Integr Med (Encinitas). 2016 Apr; 15(2):35-46.

14. Chakhtoura M.T., Nakhoul N., Akl E.A., et al. Guidelines on vitamin $D$ replacement in bariatric surgery: Identification and systematic appraisal. Metabolism. 2016 Apr; 65(4):586-97.

15. Chakhtoura M.T., Nakhoul N.N., Shawwa K., et al. Hypovitaminosis $D$ in bariatric surgery: A systematic review of observational studies. Metabolism. 2016 Apr; 65(4):574-85.

16. Jammah A.A. Endocrine and metabolic complications after bariatric surgery. Saudi J Gastroenterol. 2015 Sep-Oct; 21(5):269-77.

\section{CONCLUSION}

Overall, despite spectacular results after bariatric surgery, the bone and muscle are expected to suffer a level of deterioration, which should be taken into account for assuring an adequate quality of life and an immediate and distant good post-operatory prognosis.

17. Frederiksen K.D., Hanson S., Hansen S., et al. Bone Structural Changes and Estimated Strength After Gastric Bypass Surgery Evaluated by HR-pQCT. Calcif Tissue Int. 2016 Mar; 98(3):253-62.

18. Liu C., Wu D., Zhang J.F., et al. Changes in Bone Metabolism in Morbidly Obese Patients After Bariatric Surgery: A Meta-Analysis. Obes Surg. 2016 Jan; 26(1):91-7.

19. Scibora L.M. Skeletal effects of bariatric surgery: examining bone loss, potential mechanisms and clinical relevance. Diabetes Obes Metab. 2014 Dec; 16(12):1204-13.

20. Carrasco F., Basfi-Fer K., Rojas P., et al. Changes in bone mineral density after sleeve gastrectomy or gastric bypass: relationships with variations in vitamin $\mathrm{D}$, ghrelin, and adiponectin levels. Obes Surg. 2014 Jun; 24(6):877-84.

21. Hage M.P., El-Hajj Fuleihan G. Bone and mineral metabolism in patients undergoing Roux-en-Y gastric bypass. Osteoporos Int. 2014 Feb; 25(2):423-39.

22. Yu E.W., Bouxsein M.L., Roy A.E., et al. Bone loss after bariatric surgery: discordant results between DXA and QCT bone density. J Bone Miner Res. 2014 Mar; 29(3):542-50.

23. Vilarrasa N., de Gordejuela A.G., Gómez-Vaquero C., et al. Effect of bariatric surgery on bone mineral density: comparison of gastric bypass and sleeve gastrectomy. Obes Surg. 2013 Dec; 23(12):2086-91.

24. Brzozowska M.M., Sainsbury A., Eisman J.A., et al. Bariatric surgery, bone loss, obesity and possible mechanisms. Obes Rev. 2013 Jan; 14(1):52-67.

25. Bal B.S., Finelli F.C., Shope T.R., Koch T.R. Nutritional deficiencies after bariatric surgery. Nat Rev Endocrinol. 2012 Sep; 8(9):544-56.

26. Scibora L.M., Ikramuddin S., Buchwald H., Petit M.A. Examining the link between bariatric surgery, bone loss, and osteoporosis: a review of bone density studies. Obes Surg. 2012 Apr; 22(4):654-67.

27. Soleymani T., Tejavanija S., Morgan S. Obesity, bariatric surgery, and bone. Curr Opin Rheumatol. 2011 Jul; 23(4):396-405.

28. Vilarrasa N., San José P., et al. Evaluation of bone mineral density loss in morbidly obese women after gastric bypass: 3-year follow-up. Obes Surg. 2011 Apr; 21(4):465-72.

29. Deitel M. Bariatric surgery, proton pump inhibitors, and possibility of osteoporosis. Surg Obes Relat Dis. 2010 Jul-Aug; 6(4):461-2.

30. Viégas M., Vasconcelos R.S., Neves A.P., et al. Bariatric surgery and bone metabolism: a systematic review. Arq Bras Endocrinol Metabol. 2010 Mar; 54(2):158-63.

31. Valderas J.P., Velasco S., Solari S., et al. Increase of bone resorption and the parathyroid hormone in postmenopausal women in the long-term after Roux-en-Y gastric bypass. Obes Surg. 2009 Aug; 19(8):1132-8.

32. Vilarrasa N., Gómez J.M., Elio I., et al. Evaluation of bone disease in morbidly obese women after gastric bypass and risk factors implicated in bone loss. Obes Surg. 2009 Jul; 19(7):860-6.

33. Wang A., Powell A. The effects of obesity surgery on bone metabolism: what orthopedic surgeons need to know. Am J Orthop (Belle Mead NJ). 2009 Feb; 38(2):77-9. 